\title{
Cinematography and character depiction
}

\author{
William Francis Nicholson
}

\begin{abstract}
This essay investigates the ways in which cinematography can be used in depicting characters effectively in the motion picture medium. Since an aspiring filmmaker may be overwhelmed by the expansive field of cinematography, this essay aims to demystify and systematise this aspect of filmmaking. It combines information from written sources (mostly text books on filmmaking and cinematography) with observations made from viewing recent and older feature films. The knowledge is organised under the three main headings of lighting, camera view point and the camera's mode of perception. The outcome is an accessible and systematised foundation for film makers to consult as an entry point into understanding the relationship between character depiction and cinematography:

"Cinematography captures and expresses what a character is feeling - their attitude towards the rest of the world, their interior state” Ian Gabriel, director of Forgiveness (2004) [personal interview 2009].

\section{Introduction}

Cinematography is the aspect of filmmaking that determines how the world of a story is visually presented to an audience. The most important aspect of story telling is the portrayal of characters with whom the audience is invited to identify. Therefore I feel it will be of great value for an aspiring young filmmaker such as myself to come to understand the many elements of cinematography that can be used to depict aspects of character. The aim of this essay is to present these cinematographic elements in a coherent way that provides the filmmaker with an inventory of the 'toolbox' at her disposal.
\end{abstract}

For the purpose of conducting a systematic investigation, I will discuss cinematography according to the three main functions that the discipline serves with regards to character portrayal. The first of these is the way in which cinematography controls the appearance of a character through lighting. The second area of control in cinematography is the viewpoint from which a character is viewed - in effect, the placement of the camera in relation to an actor. The third and final area of cinematographic control lies in how the camera manipulates the mode of how characters are perceived. 


\section{Controlling the appearance of a character - lighting}

When deciding on an approach for lighting characters, the best starting point seems to be thinking about what the overall lighting style and look of the film is to be. On the broadest level, the lighting style of a film is either naturalistic or stylised. This decision is made in relation to the other elements of filmmaking, with the aim (one would hope) of best serving the narrative, thematic and aesthetic demands of the story.

Stories that have a general sense of realism - featuring characters and settings that approximate reality - will generally demand a naturalistic approach to lighting. The naturalistic approach is especially apparent in films such as Lars von Trier's Breaking the Waves (1996) and in movements such as the Danish 'Dogma 95' of the 1990s and the Italian Neorealism of the 1940s. On the other hand, stories that suggest a departure from realism will generally require a more stylised approach to lighting. Patent examples of such films include Frank Miller's Sin City (2005) and Jean-Pierre Jeunet's Delicatessen (1991).

Most films fall somewhere in the middle of the spectrum between extreme naturalism and extreme stylisation. They are naturalistic to the extent of being regarded as realistic, yet at the same time make use of stylistic elements to amplify the narrative, thematic and aesthetic demands of the story. It is within this arena of 'generally realistic' films that I will mostly be considering the use of lighting in character depiction.

An audience engages with a film when they are able to suspend their disbelief and 'buy in' to the representation of reality that the film offers. As far as lighting is concerned, the primary way of encouraging the suspension of disbelief is by having the light in the film behave similarly to the way light behaves in reality. This key principle is called motivated lighting. Lighting is regarded as being motivated when it accords to the natural behaviour of light, by being cast from a light source onto an object with natural direction and quality. Since most of our experience of life - and therefore the majority of time in our stories - takes place during the day, the most common source for motivated lighting is the sun. Kris Malkiewicz relates how 'many cinematographers call sunlight coming through windows 'sourcy' light, meaning that it is well defined in its origin' (1986: 85). Since using 'sourcy', motivated lighting encourages the suspension of disbelief it is an important factor that leads an audience to engage with a character. In other words, if a character is lit in a way that conforms to the natural laws of light, that character is more likely to be taken seriously by an audience.

However, by occasionally departing from a strict adherence to motivated lighting, the director and cinematographer are able to amplify specific moments in the story. Jennifer van Sijll points out two examples of such departures from motivated lighting (2005: 198). The first occurs in Oliver Stone's Natural Born Killers (1994), where during a flashback to Malory's youth the lighting changes from motivated to typical television studio lighting, which is characterised by being flat, directionless and low-contrast with virtually no shadows. Here the departure from motivated lighting alerts the audience that the 
flashback is a departure from 'pure' realism, offering insight into the subjective memories of the character. Television lighting is usually associated with the relatively light content of sitcoms and family dramas. Here the convention is subverted by the anything-but-light content of Malory's troubled youth - signalling that the way Malory sees the world is significantly different to 'normal' perception.

Van Sijll's second (and more subtle) example of a departure from motivated lighting is from Luc Besson's The Professional (1994) - where Natalie Portman's character is standing outside the apartment of Jean Reno's character, desperately wanting him to open the door. When Reno finally opens the door, Portman is bathed in light that is too bright to naturally come from inside Reno’s dark apartment. Here, the filmmakers departed from a strictly motivated use of lighting in order to convey something about Portman's character: her joy at Reno’s willingness to help her.

Motivated lighting can also be withheld from a scene in order to convey something specific about a character. In Spike Jonze’s Adaptation (2002) the cinematographer Lance Accord "never wanted to have a feel of direct sunlight coming into Charlie's room [played by Nicolas Cage]" as part of the process of depicting Charlie as being "holed up" in his room and isolated from society (26).

Once the director and cinematographer have come to agreement on the degree of naturalism and stylisation they wish to employ, they can move on to making more specific decisions about how their film will be lit.

Firstly, they must decide when lighting is to be high-key and when it is to be low-key. Herbert Zettl distinguishes these concepts as follows: while high-key lighting features "an abundance of bring, usually slow falloff illumination and a light background”, low-key lighting is characterised by "fast falloff illumination [that is] highly selective, leaving the background as well as part of the scene predominantly dark" (1999: 28-31). Zettl makes a further distinction between chiaroscuro and flat lighting, but the difference between these principles and the concepts of high- and low-key lighting is not entirely clear to me. Zettl defines chiaroscuro lighting as an approach that "emphasises contrasting light and shadow areas and is fast falloff lighting" and flat lighting as "slow falloff lighting [where] the shadows are highly transparent or, for all practical purposes, nonexistent” (44). The distinction between high-key and flat lighting is useful if one considers that a high-key scene could still have a significant amount of contrast (as long as most of the scene is brightly lit). Similarly, a scene could be low-key and still flat (if the few areas that are indeed lit are flat).

Since I started studying film I had been suspicious that the notions of high-key and lowkey were too vague, but I could not say exactly why. Now that I have compared these notions to chiaroscuro and flat lighting, I think it becomes apparent that high- and lowkey are indeed too vague to be truly useful. This is because these terms conflate two 
concepts that should be kept separate, namely the distribution of light in a scene and the contrast of a scene. Hence for the purpose of this discussion I will keep these two concepts separate rather than combining them under the umbrella terms of high- and lowkey lighting.

It seems that chiaroscuro lighting offers greater range of what it can convey about a character, whereas flat lighting is limited to two basic possibilities: showing the character as living happily in their bright, shadow-less world (abundantly used in romantic comedies); or presenting an ironic subversion of this idea by juxtaposing flat lighting with content that runs against the expectations of happiness - as illustrated by the abovementioned example from Natural Born Killers.

Zettl points out the five central functions of chiaroscuro lighting (which he also calls Rembrandt lighting) as being:

Organic (to make a scene look realistic), directional (to lead the eye to specific picture areas), spatial/compositional (to define space and contribute to a balanced pictorial composition), thematic (to emphasise the theme or story being told), and emotional (to establish or emphasise a mood) (44)

We have already addressed the organic function of film by investigating the effect of motivated lighting on the suspension of disbelief (as well as the deliberate departure from motivated lighting), thus we will move on to consider the directional function of lighting.

In the medium of painting, the use of lighting designed to direct a viewer's gaze was mastered centuries ago by painters like Caravaggio. Filmmakers have drawn from this vast body of mastery to apply similar principles to filmmaking. A brilliant example occurs in Orson Welles' tour de force Citizen Kane (1941) where, in the famous long shot where the boy Kane's mother is 'signing him away', the boy is seen in the brightest light in the far background. The viewer's eyes are directed from the foreground, where the contract is being signed by Kane's mother, to the background where the boy is playing. It presents the viewer with a question-answer composition of 'what is she signing? Oh, she is signing over the custody of her son'.

Zettl's notion using lighting to attain spatial/compositional balance is not particularly relevant to character depiction unless this balance, or lack thereof, is used to convey something about characters. An example arises in one of the last scenes of Francis Coppola's Apocalypse Now (1979), where Willard (Martin Sheen) finally kills Kurtz (Marlon Brando). Both characters are shown in frames that are illuminated by glowing smoke in one half but entirely dark in the other half. This compositional imbalance could be interpreted as signifying the psychological instability of both men, and the sense of moral ambiguity (or even nihilism) that both men feel. 
Blain Brown points out how lighting can effectively convey a thematic aspect of a character, by referring to Barry Levinson's The Natural (1984). In this baseball film there is a strong binary code of good versus evil. Generally speaking, whenever the protagonist Roy diverges from what ought to be done, he and his environment are treated with dark, low-key lighting. He is tempted by The Lady in Black, who is mostly backlit or silhouetted to convey her evil intentions. Similarly, The Judge - who is the central antagonist of the film - is seen mostly in his dark office, where only slits of light seep in through the Venetian blinds (Brown, 162).

Zettl's final function of chiaroscuro lighting is indeed a helpful one - conveying the emotional meaning of a scene. Van Sijll points out two examples of where chiaroscuro is effectively employed to convey character interiority. The first occurs in the dinner scene in Sam Mendes' American Beauty (1999), where the warm, pleasant effect that candlelight has on the faces of the family members is subverted by the family's dialogue, which reveals that it is in fact a dysfunctional household. The candlelight renders some area of the dining room darker than others, suggesting that there are things this family keeps concealed. The second example is taken from Apocalypse Now, where Captain Kurtz appears for the first time. He sits up on his bed in the shadows and only the side of his bald head comes into the light. There is very fast falloff, sharply dividing the illuminated side of his head from his face, which is shrouded in darkness. This use of chiaroscuro lighting indicates the inner darkness of Kurtz to the viewer, whilst also mimicking Captain Willard's uncertainty at what to expect from Kurtz - he is unable to 'read' his expressions. In a story about war and insanity, this fragmentation of character through lighting is an excellent use of the medium. Lighting is a powerful tool in conveying the way a character feels because, like music, "it seems to be able to bypass our usual perceptual screens - our rational faculty with its critical judgement - and affect us directly and immediately” (Zettl, 18).

I have already touched upon the concept of falloff, which is the rate of change between light and dark areas on an object. A concept that goes hand-in-hand with falloff is quality, which refers to the directionality and intensity of light. The quality of light can be either hard or soft, or (in most cases) somewhere in between. Hard lighting has sharply defined shadows (hence fast falloff), high contrast, black shadows, and it emanates from a single small source (like the noonday sun); whereas soft light has gradual falloff with indistinct edges, low contrast, lighter shadows, and emanates from large, diffused sources (like an overcast sky or setting sun).

Using hard lighting on character generally makes the character seem 'harder'- their facial contours and shadows become more distinct. Hard lighting can thus be used to suggest that a character is strong, determined, troubled, angry and so on. In Apocalypse Now the lighting on Captain Willard is at its hardest when he finally arrives at Kurtz's compound, which is the arena for his final psychological struggle in resisting insanity and killing Kurtz. Contrary to hard lighting, soft lighting flattens out facial contours and can be used to make a character seem docile, weak, content, tender etc. This convention is often 
parodied, as seen in the lovemaking scene in Ben Stiller's Zoolander (2001). However, it can also be used effectively in a serious context as is done in Alan Pakula's Sophie's Choice (1982). Malkiewicz points out how flat lighting is used in the library scene to “create a mood of dejection and alienation” in Meryl Streep’s character. Although soft light is often criticised because of its 'plainness' and associations with television, distinguished cinematographer Caleb Deschanel insists that "the argument between hard and soft light is kind of weak because in a sense you really make your judgement based upon whatever the story is” (Malkiewicz , 85). Malkiewicz makes the helpful addition that "if you go too soft in the lighting, it just becomes boring. The difficult thing is really to light softly but to create a contrast at the same time” (85).

Along with the quality of light, the other determining factor of lighting design is the direction (or most often the directions) from which a scene is lit. It is logical to start discussing lighting directions by first mentioning the main source of light in a scenecalled the key light. The position of the key light in relation to the actor determines the shape and size of the attached shadows on the face and body of the actor. Malkiewicz explains that "the general direction and angle of the key light will establish the mood in which the face is lit" (129). He points out the most common convention, whereby "good people are lit from heaven and bad people are lit from hell” (133). Cinematographer Darius Khondji is unashamed in his use of this dualistic convention in Delicatessen (1991): "I lit the story in a very basic Manichean way. The butcher (Jean-Claude Dreyfus) was evil and I would light him from below, giving him more of a gargoyle look” (Ballinger, 72).

The second light commonly used in a lighting setup is the fill light. As the name suggests this light serves to fill some light into the shadows created by the key light. A greater amount of fill light causes a softer, flatter look, whereas minimal or no fill light results in a hard, chiaroscuro look. Since I have already gone with some detail into the difference between hard and soft light, I will move on to discuss the next directional light - the backlight.

The backlight is generally used to separate the character from the background, by creating an outline around them. Backlighting has been exhaustively used to create the saintly 'halo effect' seen in television shows like Touched by an Angel. This is not its only use though - in Adaptation Lance Accord “put a backlight behind Charlie's [played by Nicolas Cage] hair to show the thinness of it and when we had him looking at his most unappealing we felt like we were doing a good job” (Ballinger, 25).

The final directional light that is generally used in motion picture lighting is the background light, which - as the name implies - illuminates the background. Generally speaking, a background should be a little darker than characters so that the audience's gaze is not diverted from the characters. This points to how this convention can be disregarded to convey a specific meaning - for example, if a cinematographer wished to suggest a character's feelings of insignificance by placing her against a brighter, busier 
background. Cinematographer Jordan Cronenweth is of the opinion that "sometimes it is nice to have a face that is just almost melting into the background” (Malkiewicz , 93). Brown cites another use of background lighting in Orson Welles' The Lady From Shanghai (1947), where the backlighting from an aquarium just about silhouettes the characters to create an ominous mood, suggesting that the lady is perhaps a femme fatale (50). In addition to the basic directional lights of key, fill, backlight and background light are other specialised lights. The most common of these is the eye-light which is a light (or sometimes lights) dedicated to illuminating an actor's eyes in a specific way. Returning to Khondji's lighting design in Delicatessen, he speaks of how he "always lit the butcher's eyes with a dash of light, a small fluorescent light” (Ballinger, 72). In the opening scene of Apocalypse Now, Captain Willard's incipient insanity is amplified by an extreme close up on his eyes, which are illuminated by light from Napalm fire. This gives them a glassy, animalistic look that accentuates dehumanising effects of war.

Another common specialised light is the kicker or rim, which usually casts a bit of light from a three-quarter back position. In the same scene from Sophie's Choice mentioned earlier, a kicker is used to give the "unfriendly library clerk... a more self-assured look" (Malkiewicz, 90).

Lighting can emanate either from off-screen sources or from within the frame. The latter type of light source is commonly known as a practical light. Brown outlines two of cinematographer Caleb Deschanel's uses of practicals in The Natural. The first occurs when Roy regains his fame as a baseball player, which is accentuated by "a montage sequence of flashbulbs popping, symbolising fame, celebrity, glamour and the seduction of the fast life which will distract him from baseball” (163). The second example takes place in the fulfilment scene, where "Roy slams a home run right into the stadium lights, which shatter and short-circuit, sending a shower of sparks onto the field... Roy and his celebrating teammates are enveloped in these glowing fireworks, as if miniature stars of glory are raining on them” (165).

Zettl references two uses of practicals by Frederico Fellini that communicate on a somewhat more cerebral level than in The Natural. In La Dolce Vita (1960) "he shows a television remote unit covering the events of an alleged miracle... Fellini cuts in closeups of lighting instruments being turned on... to counterpoint... the uncritical world of blind faith, and the analytical and soulless modern age as symbolised by the lighting instruments and cameras”. In 81/2 (1963) "Fellini uses many lighting instruments arranged in large circles, illuminating representatives of humanity who, following the director's orders, march willingly, like circus clowns... a strong reminder... that we may discover that we are all part of a big cosmic joke” (30).

I have mostly been discussing the functions of light within a scene, but in creating meaning light is only as important as its binary opposite - darkness. Malkiewicz points out that " "what you do not see is equally important as what you do see'. The light is there to direct the viewer's attention, the darkness is there to stimulate his imagination” (2). In 
the scene from Apocalypse Now that I cited earlier - where Kurtz is revealed for the first time - most of his face is left in darkness for an extended period of time. This intensifies the audience's interest in the character by forcing them to wait before seeing his features in the light. It reinforces his sense of mystery and insanity, and suggests (especially in harmony with his ironic cleansing ritual) that he is unable to come into the light because it may expose his bloody deeds.

In the Natural there is recurring lighting motif in the protagonist's movement from darkness to light when he is on 'the right path'. The motif is established when he first returns to the ballpark and moves from total darkness to emerge "in to sunlight as he enters the ballpark: he is home, where he belongs" (162). The motif recurs a few times, like a when Roy confesses his dark past to Iris and "as he ends his confession they emerge into full daylight” (163).

In the scene where the bathroom floods in Delicatessen, Khondji deliberately lit the room so that it would have no shadows. With the butcher coming after the hero and heroine, Khondji wanted to amplify the characters' terror by denying them any place to hide in a fully lit room (Ballinger, 72).

\section{Controlling the viewpoint from which a character is seen - camera placement}

Now that I have discussed the control that cinematography exercises over the appearance of a character through the use of lighting, I will move on to discuss the viewpoint of the camera. Alexander Mackendrick emphasises the importance of camera placement as the primary shaping force of the narrative point of view:

At each particular moment of any given scene, the position of the camera is a point in time and space from where the Invisible Imaginary Ubiquitous Winged Witness, the observer of the action, implies a specific point of view. It is from this spot where the audience views the story, from where the Witness prompts the audience to feel sympathy for once character over another (222).

Steven Katz agrees with this function of the camera's viewpoint, that it "determines who the viewer identifies with" and that "each shot in a film expresses a point of view, and in narrative film the point of view changes often, sometimes with each shot” (1991: 267).

The three main narrative points of view that Katz outlines are the first person subjective, the third person restricted and the omniscient point of view. The first person subjective point of view occurs when we see the story world through the eyes of a character. An example of a film that is almost entirely shot from subjective camera placements is Julian Schnabel's The Diving Bell and the Butterfly (2007). However, such an extensive use of the first person point of view is the exception and not the rule, since "we are only given the visual point of view of a character and are deprived of seeing his or her reactions through facial and other gestures” (Katz, 267). 
Films are mostly a combination of third person restricted and omniscient points of view, garnished with moments of first person points of view. As Nicholas Proferes observes, "most of the time the narrator will be speaking with an 'objective' voice" (2001:38). According to Katz' paradigm, the only difference between the restricted third person and the omniscient points of view is that the omniscient point of view offers the audience access to the thoughts of characters through flashbacks, voiceover narration and similar devices (267-268).

On a tangential note, since we are discussing the relationship between cinematography and character, it is interesting to think of the camera itself as a type of character. It is the eye of the storyteller that has its own prejudices and assumptions when it looks at the story world (mostly the sum total of the director and cinematographer's prejudices and assumptions). Nicholas Proferes raises the question of whether the camera is "curious, playful, omniscient, lyrical?” (38). Director Alfonso Cuaron has developed a trademark preference for very long shots with inquisitive Steadicam movements, as if the camera is moseying around casually whilst watching the action (see Cuaron's Y Tu Mama Tambien [2001]).

Our level of identification with a character is determined by where the camera is placed in relation to them. Katz points out that "generally speaking, the closer the sightline of a player in a close-up is to the camera, the greater the degree of viewer identification" (269). This principle is powerfully demonstrated in the breakfast scene in Apocalypse Now where Martin Sheen stares directly into the camera - making the viewer feel a great sense of identification with his situation. It is almost as if Captain Willard is looking at the audience in hope of finding some sympathetic eyes. Mackendrick explains that when we see a character's "face directly, we feel much more of the impact of the subject's personality” (225). This aligns with the thoughts of Joseph Mascelli in his classic book The Five C's of Cinematography: "the viewer should be brought into the picture... from an inside angle” (1965: 65).

In addition to placing the camera close to an actor's eye-line, a filmmaker can also heighten the level of audience identification by offering the viewer shots that align with a character's perceptions of the story world. Proferes suggests that "the subjective camera allows us to see what our subject is actually experiencing” (38). For a good example of this we need look no further than the same breakfast scene in Apocalypse Now, where there is a tight shot of the crawfish from Captain Willard's point of view. The viewer is made aware of the almost nauseating effect that the briefing to kill Kurtz is having on Willard. From his perspective even the crawfish look ominous and threatening on account of the disturbing news about Kurtz and the fearsome mission that lies ahead.

The next major area of control that a filmmaker has over the narrative viewpoint is the shot scale. In most instances, the more of the frame is taken up by an actor, the greater the sense of viewer identification with that character. Mackendrick observes that "if one character is seen in a close-up and the other in a medium shot, our feelings of sympathy 
and/or identification are with the figure seen at the closer distance” (225). This does not mean, however, that wide shots cannot also be used to provide insight into characters. For example, in Jane Campion's The Piano (1993) we see the protagonist alone on the beach with her daughter and piano in an extreme long shot. This vista creates a sense of the character's desire for freedom from societal constraints and perhaps also her vulnerability in the wilderness of New Zealand.

The next aspect of the camera's viewpoint which is significant for character depiction is the camera's height and, in close correlation, its angle. A camera can be placed at the eyelevel of an actor, or it can be placed in varying degrees above or below for a high or low angle respectively.

Director Edward Dmytryk vehemently argues that an eye-level shot should be avoided at all costs simply due to being the "dullest possible shot" (Proferes, 44). He advises that the camera usually be placed either just above or just below eye level. There are some practical reasons for choices about camera height, for example a "slightly lower angle... allows the camera to get a better look into the actor's eyes, which is, in film, a powerful way of communicating” (Proferes, 40).

Generally speaking, a high angle shot on a character suggests that the character is somehow weak, inferior, beleaguered or a similar type of actual or perceived deficiency. In the scene at the "El Rancho" in Citizen Kane, Charles Kane’s ex-wife is framed in a high angle shot to suggest that her life has fallen apart. Lance Accord talks about the use of high angle shots in depicting the character of Charlie Kaufman in Adaptation: "we tried to belittle him by looking down on him a lot, to make him feel small and somewhat pathetic” (Ballinger, 25).

Conversely, a low angle shot is used to suggest that a character bears authority, stature, power or similar traits of actual or perceived advantage over others. In Citizen Kane, when the protagonist is at the height of his career he is framed in a low angle shot to convey his pride and power.

Camera height and angle can be used in more creative ways than the simple convention of 'high-angle equals advantage, low angle equals deficiency'. In Sidney Lumet's 12 Angry Men (1957) the film starts with shots that are above eye level and, as the film progresses, the camera gradually moves down, through normal eye-level in the second act towards a low-angle position in the third act. By the time the film reaches it climax, the ceiling becomes visible behind the characters - making it seem like the ceiling is closing in on them, just like the pressure of the narrative (Proferes, 44).

The final important way in which the viewpoint of a camera can affect character depiction is the camera's movement in relation to the character. The camera can pan along its vertical axis, either to the left or right. A pan serves to reveal new information to the audience without resorting to a cut. Van Sijll cites the use of a pan in Kevin Costner's 
Dances with Wolves (1990), where Kevin Costner's character insists that he does not want his leg to be amputated. His statement is followed by a pan to the right to reveal the dubious medical equipment that would be used for the amputation procedure (170). Here the pan mimics the character's sense of fear and determination against the amputation.

The camera can also tilt along its horizontal axis, either up or down. The tilt-up is a classic device used to gradually introduce a new character, or to reintroduce a character that has just undergone significant change (often after a montage). The convention is used in a novel way in The Professional to introduce Natalie Portman's character. Van Sijll comments on how this tilt up is interesting because it gradually takes the audience through the paradoxical wardrobe of Portman's character, from toes to head (172). She wears heavy, adult boots over comical, childlike stockings. Above the stockings she wears a womanly dress and above that is distinctly teenage jewellery around her neck. Finally we see a mature-looking choker around her throat, a made-up face and a bob haircut, which are all distinctly adult.

The camera can move along a straight line in a tracking or dolly shot. A tracking shot can serve a variety of purposes, but is mostly used to either follow a moving character or to offer a dynamic point of view on a character. An example of the former device is often seen in newsroom dramas - like Alan Pakula's All the President's Men (1976) - where characters talk while walking briskly past a roomful of reporters hard at work at their desks. This kind of shot conveys the dynamic lifestyle of the characters and a sense of their drive to excel, hurrying past all their stationary peers. An example of moving the camera to offer a dynamic perspective on a stationary character can be seen in Ian Gabriel's Forgiveness (2004), where the protagonist Tertius Coetzee sits motionlessly on a chair while the camera slowly tracks around him to suggest his inner turmoil and uncertainty.

A circular tracking shot can also be used to great effect, as Van Sijll points out in Quentin Tarantino’s Reservoir Dogs (1992), where the device is used to mimic all the characters' suspicion of one another.

In addition to moving horizontally, the camera is also able to move vertically up or down in a crane shot. As with tracking shots, crane shots can offer a multitude of different meanings, but one common use of the device is what Jeremy Vineyard calls the 'craneup, move away'. As the name suggests, in this kind of shot the character moves away from the camera while the camera pans up. This shot is often used in the final scene of a film, where the protagonist has achieve her narrative goal and can now move on to her next challenge, which lies beyond the scope of the story. This device is used to great effect in the final shot of Frank Darabont's The Shawshank Redemption (1994) where Red (Morgan Freeman) walks along the beach to meet up with Andy (Tim Robbins). The upward motion of the crane amplifies the sense of hope and freedom that both men have for the future. 


\section{Controlling the mode of perception through which a character is seen - elements within the camera}

The final aspect of cinematography that I will discuss is what I term the mode of perception. This refers to the ways in which perception is controlled from within the camera itself, through the use of lenses, focus and shutter speed.

Lenses, when used effectively, are a powerful tool for shaping the audience's perception of a film. Lenses range from wide to telephoto, with normal falling in-between. As the name implies, a wide lens captures a wide section of visual information; whereas a telephoto lens captures a narrower section of visual information.

This is not the only difference between these two types of lenses. Michael Rabiger explains that a wider lens "changes the apparent distance between foreground and background, making it appear greater", whereas a "telephoto lens does just the opposite, squeezing foreground and background close together” (2003:412).

These properties of lenses have significant implications for character depiction. In shots with wide lenses, the characters will be seen as being separated from objects on other planes of depth. Brown cites an example of this device in Citizen Kane, where "Welles uses the exaggerated distances of wide lenses to separate Kane from other characters in the scene, thus emphasising his alienation and self-absorption” (49).

Telephoto lenses can also be used to great effect. The compression of planes of depth "can be used for many perceptual purposes: claustrophobic tightness of space, making distant objects seem closer and heightening the intensity of action and movement" (Brown, 49). Movement towards or away from a long lens seems less dynamic than real life. Van Sijll mentions how this trait of the telephoto lens is used to great effect in Mike Nichols’ The Graduate (1967), where Ben (Dustin Hoffman) runs with great haste towards a telephoto lens to profess his love to Elaine Robinson (Katharine Ross). The long lens makes it appear as though Ben is hardly making any progress as he runs - a metaphor for his directionless life.

In 12 Angry Men, the aforementioned device of gradually shooting from a lower angle was accompanied by gradually shifting from wide to telephoto lenses. By doing this Sidney Lumet could increase the sense of pressure on the characters by diminishing the perceived distance between characters and the walls behind them - making it seem like the walls were quite literally closing in on them (Proferes, 45).

In addition to the effect that lenses have on planes of depth, there is also the distorting effect of wide lenses that is at the disposal of the filmmaker. In Darren Aronofsky's Requiem for a Dream (2000) the delirium in the mind of Sara Goldfarb (Ellen Burstyn) is signified by capturing her distorted image through a very wide fish-eye lens. 
The next device in the filmmaker's toolbox is focus. A cinematographer may choose to render a scene in either deep or shallow focus. Deep focus offers the audience more than one plane of depth in sharp focus, thus allowing them to decide where to fix their gaze. Shallow focus directs the viewer's gaze onto the plane that is in sharp focus. Within a shot the plane that is in sharp focus may change through the use of a focus rack or focus pull. In addition to this function of directing the viewer's gaze, "shallow depth of field can isolate the subject” from the background (Brown, 51).

A shot may also be deliberately rendered in out of focus in order to communicate the interior state of a character. In Adaptation Accord and his focus puller accidentally shot Meryl Streep out of focus in a scene where her character, Susan Orleans, was under the influence of drugs. The shot ended up being accepted by Accord because of its significance in communicating Orleans' subjective experience. A similar device is used (presumably deliberately) in Apocalypse Now in the aforementioned breakfast scene. Willard moves in and out of focus to convey his unstable state of mind.

The final element I will consider that affects the camera's mode of perception is the shutter speed, referred to more accurately as the shutter angle. The angle at which the camera shutter is tilted determines how long each frame is exposed to the incoming light. If the frame is exposed for a relatively long period of time, moving objects will be more blurry and indistinct. If the frame is exposed for a relatively short period, moving objects are captured distinctly.

Shutter speed can be used to convey the interior state of a character. In Steven Spielberg's Saving Private Ryan (1998) the sense of adrenaline of battle is accentuated by the use of a fast shutter speed, which captures bits of dust and debris flying through the air. Cinematographer John Mathieson talks about how he used 'narrow shutters' on Ridley Scott's Gladiator (2000) in order to mimic the characters' subjective experience of war, to "give the impression of what it's like to be in a battle, to be so exhausted, frightened, lost” (Ballinger, 111).

\section{Conclusion}

In this essay I have demonstrated, with the accompaniment of examples from existing films, how cinematographic elements may be used by the filmmaker to convey aspects of character. I have systematised my discussion by compartmentalising it into three main elements of cinematography: lighting, camera placement, and in-camera effects.

\section{Author details}

William Francis Nicholson

Email: williamnicholson3@gmail.com

Postal address: 524 Helderberg Village, private bag x19, Bakkerskloofweg, Somerset West 1739

Phone: 0722521067

Institution: AFDA Film school Honours 


\section{References}

Ballinger, A. 2004. New cinematographers. London: Laurence Kind Publishing

Brown, B. 2002. Cinematography: theory and practice. Boston: Focal Press

Cronin, P (ed.) 2004. On Filmmaking: An introduction to the craft of the director NewYork: Faber and Faber

Gabriel, I. 2009. Personal interview, Cape Town

Katz, S. 1991. Film directing shot by shot: visualising from concept to screen. Studio City: Michael Wiese

Malkiewicz, K. 1986. Film lighting: talks with Hollywood's cinematographers andGaffer. New York: Prentice Hall Press

Mascelli, J. 1965. The five C’s of cinematography. Beverly Hills: Silman James

Proferes, N. 2001. Film directing fundamentals: from script to screen. Boston: Focal Press

Rabiger, M. 2003. Directing: film techniques and aesthetics. $3^{\text {rd }}$ ed. Boston: Focal Press

Van Sijll, J. 2005. Cinematic storytelling: the 100 most powerful film conventions every filmmaker must know. Studio City: Michael Wiese

Vineyard, J. 1999. Setting up your shots: great camera moves every filmmaker should know. Studio City: Michael Wiese

Zettl, H. 1999. Sight sound motion: applied media aesthetics. Belmont: Wadsworth Publishing Company

\section{Filmography}

Steven Spielberg’s Saving Private Ryan (1998)

Lars von Trier’s Breaking the Waves (1996)

Frank Miller’s Sin City (2005)

Jean-Pierre Jeunet’s Delicatessen (1991)

Oliver Stone’s Natural Born Killers (1994) 
Luc Besson’s The Professional (1994)

Spike Jonze’s Adaptation (2002)

Orson Welles’ Citizen Kane (1941)

Francis Coppola’s Apocalypse Now (1979)

Barry Levinson’s The Natural (1984)

Sam Mendes’ American Beauty (1999)

Ben Stiller’s Zoolander (2001)

Alan Pakula's Sophie’s Choice (1982)

Orson Welles' The Lady From Shanghai (1947)

Frederico Fellini’s La Dolce Vita (1960)

Frederico Fellini's 81/2 (1963)

Julian Schnabel's The Diving Bell and the Butterfly (2007)

Alfonso Cuaron’s Y Tu Mama Tambien (2001)

Jane Campion’s The Piano (1993)

Sidney Lumet’s 12 Angry Men (1957)

Kevin Costner's Dances with Wolves (1990)

Alan Pakula's All the President's Men (1976)

Ian Gabriel’s Forgiveness (2004)

Quentin Tarantino’s Reservoir Dogs (1992)

Frank Darabont’s The Shawshank Redemption (1994)

Mike Nichols’ The Graduate (1967)

Darren Aronofsky's Requiem for a Dream (2000) 
doi: $10.5789 / 4-2-6$

Ridley Scott’s Gladiator (2000) 